\title{
Application of sodium- and biogenic sulfide to the precipitation of nickel in a continuous reactor
}

\author{
Flávia D. Reis ${ }^{1}$, Adarlene M. Silva ${ }^{2}$, Emanoelle C. Cunha ${ }^{2}$, Versiane A. Leão* \\ Bio and Hydrometallurgy Laboratory, Department of Metallurgical and Materials Engineering, Universidade Federal de Ouro Preto, Campus Morro do Cruzeiro, \\ Ouro Preto, MG 35400-000, Brazil
}

\section{A R T I C L E I N F O}

\section{Article history:}

Received 27 November 2012

Received in revised form 13 June 2013

Accepted 23 September 2013

Available online 30 September 2013

\section{Keywords:}

Precipitation

Sulfide

Precipitation kinetics

Nucleation

Crystal growth

Agglomeration

\begin{abstract}
A B S T R A C T
Attention has been focused in recent decades upon the precipitation of metal sulfides from acid mine drainage (AMD) and pregnant leach solutions, due to the advantages of the sulfide precipitation process over traditional methods employing hydroxides. The aim of this work was thus to explore technologies for the precipitation of valuable metals, such as nickel using such sulfides (as either $\mathrm{Na}_{2} \mathrm{~S}$ or biogenic sulfide). The recovery of nickel sulfide was improved when the initial $\mathrm{pH}$ of the solution containing each metal was set to 7 . In such a condition the removal efficiency of nickel was $99.9 \%$, corresponding to a residual level of $0.13 \mathrm{mg} \mathrm{L}^{-1}$ for nickel in solution. Kinetic parameters for precipitation were determined from the particle size distributions (produced in an MSMPR reactor) using the method of moments, where the growth and nucleation rates, as well the agglomeration kernel, were calculated. The precipitation of nickel at an initial $\mathrm{pH}$ of 7 showed a nucleation rate value of $8.16 \times 10^{18} \# \mathrm{~m}^{-3} \mathrm{~s}^{-1}$, the highest volumetric growth rate $\left(1.03 \times 10^{1} \mu \mathrm{m}^{-3} \mathrm{~s}^{-1}\right)$ and agglomeration kernel of $9.71 \times 10^{-23} \mathrm{~m}^{3} \#^{-1} \mathrm{~s}^{-1}$. The biogenic sulfide was a suitable alternative to sodium sulfide for nickel removal. Both sodium sulfide and biogenic sulfide can be utilized to precipitate nickel as millerite (NiS), allowing the effluent compliant with environmental legislation.
\end{abstract}

(c) 2013 Elsevier B.V. All rights reserved.

\section{Introduction}

Several industrial processes, particularly those related to the metallurgical and mining industries, produce acid effluents containing large amounts of dissolved metals, which can cause serious environmental damage $[1,2]$. In the mining processes, an important environmental problem is acid mine drainage (AMD) [3-5], which occurs when sulfide minerals are exposed to air and water and undergo oxidation, producing sulfuric acid and contaminating water bodies with toxic metals, sulfates and other pollutants [6].

Many technologies are being developed for and applied to the treatment of metal-laden effluents, and a significant body of research has investigated the treatment of such wastewaters [7]. Physicochemical and biological methods include precipitation

\footnotetext{
* Corresponding author. Address: Bio and Hydrometallurgy Laboratory, Department of Metallurgical and Materials Engineering, Universidade Federal de Ouro Preto, Campus Morro do Cruzeiro, s.n., Bauxita, Ouro Preto, MG 35400-000, Brazil. Tel.: +55 313559 1102; fax: +55 3135591561 .

E-mail addresses: versiane@demet.em.ufop.br, versiane.ufop@gmail.com (V.A. Leão).

1 Department of Chemistry, Biotechnology and Bioprocess Engineering, Universidade Federal de São João del Rey, Campus Alto Paraopeba, Rodovia MG 433, Km 7, Ouro Branco, MG, 36420-000, Brazil.

2 Tel.: +55 313559 1102; fax: +55 3135591561 .
}

(chemical or electrochemical), solvent extraction, electrodeposition, ion exchange, (bio)sorption and flotation [2].

Due to the familiarity of the industry with it, precipitation is one of the first technologies to be tested, particularly for large volumes of effluent and high pollutant concentrations. Precipitation is a complex process that is influenced by several parameters, including nucleation, growth and, eventually, agglomeration and breakage of particles [8]. In hydrometallurgical processes and in the treatment of metal-containing effluents, the use of sulfide precipitation for recovering metals has received considerable attention because of the advantages offered by sulfide precipitation over traditional methods employing precipitation as metallic hydroxides [7]. In line with this trend is the use of biogenic sulfide $\left(\mathrm{H}_{2} \mathrm{~S}\right)$ as a substitute for chemically produced sulfide $\left(\mathrm{Na}_{2} \mathrm{~S}, \mathrm{H}_{2} \mathrm{~S}\right.$ or $\left.\mathrm{NaHS}\right)$. Hydrogen sulfide can be produced on-site by sulfate-reducing bacteria (SRB) through a process that allows safer handling and eliminates the need for storage of such a hazardous chemical [9].

Lewis [10] comprehensively reviewed the precipitation of metal sulfides, considering the solubility and stability of the sulfide ion along with its complexes with metal ions. The authors addressed the kinetics of metal precipitation, the characterization of the solid product and the industrial and environmental applications of this technology. The author considered nickel precipitation to be a problematic process, being strongly $\mathrm{pH}$-dependent. Other authors also 
suggested that $\mathrm{pH}$ control is essential for an effective precipitation of metal sulfides $[2,11]$. In the studies reported by Cao et al. [3], when assessing the influence of $\mathrm{pH}$ and temperature over the removal of such metals as $\mathrm{Cu}^{2+}, \mathrm{Fe}^{2+}$ and $\mathrm{Ni}^{2+}$ by precipitation with sulfide, higher temperatures were found to be beneficial only for nickel precipitation. The efficiency of the process was also strongly influenced by the concentration of sulfide ions (i.e., supersaturation). In another study, Lewis and van Hille [12] investigated the effect of excess sulfide on nickel precipitation from a synthetic solution with a concentration of $2000 \mathrm{mg} \mathrm{L}^{-1} \mathrm{Ni}^{2+}$. Under such experimental conditions, the amount of nickel remaining in solution was large $\left(65.7 \mathrm{mg} \mathrm{L}^{-1}\right)$, and the authors attributed this outcome to the formation of nickel complexes with the bisulfide ion. In another study, Lewis and Swartbooi [13] investigated nickel $\left(2000 \mathrm{mg} \mathrm{L}^{-1} \mathrm{Ni}\right.$ ) precipitation in fluidized bed reactors. The authors argued that this type of reactor was not adequate for sulfide precipitation because the removal efficiency was only $85 \%$ for nickel. Karbanee et al. [14] studied a continuous process for sulfide precipitation from synthetic nickel solutions containing $200 \mathrm{mg} \mathrm{L}^{-1} \mathrm{Ni}^{2+}$, at $25^{\circ} \mathrm{C}$. When the experiments were carried out under conditions of excess sulfide ([Ni]:[S] equal to $1: 1.5$ ), the efficiency of nickel removal was only $70 \%$, and the solution $\mathrm{pH}$ was 11.5. For a stoichiometric ratio ([Ni]:[S] of $1: 1$ ); and $\mathrm{pH} 9$, the metal removal was complete. Sampaio et al. [15] assessed zinc and nickel separation by sodium sulfide in an MSMPR (Mixed Suspension Mixer Precipitation Removal) reactor and stated that the best results were achieved at pH 6 and the stoichiometric ratio between both species.

The determination of nucleation and growth rate, as well as agglomeration parameters, was carried out in a study addressing the precipitation of zinc sulfide in an MSMPR reactor [8,16], where high supersaturation resulted in higher nucleation rates. Similarly, van Hille et al. [7] reported that high levels of supersaturation induced homogeneous nucleation, and therefore finer precipitates were formed. The homogeneous nucleation may have contributed to inefficiencies in the precipitation process.

The development of technologies for on-site sulfide generation (sulfate reduction) has renewed the interest in sulfide precipitation aiming at both metal recovery and effluent treatment. Copper and zinc precipitation has been studied extensively, but nickel has been addressed less frequently. Nickel sulfide is highly reactive, and therefore the particle size distributions PSD are not easily determined, meaning that nucleation and growth rates are seldom found in the literature. This work therefore investigated the application of biogenic sulfide for nickel precipitation, evaluating the kinetic factors involved in the process.

\section{Modeling precipitation in MSMPR reactors}

Supersaturation (S), the driving force of precipitation, was calculated according to Eq. (1), where equilibrium conditions are represented by the subscript eq:

$S=\frac{a_{ \pm}}{a_{ \pm, e q}}$

where $a_{ \pm}$is the mean ionic activity of NiS, which may be written as:

$a_{ \pm}=\sqrt{a_{\mathrm{Ni}^{2+}}^{1} \cdot a_{S^{2-}}^{1}}$

The solubility product of $\mathrm{NiS}\left(K_{s p}\right)$ can be defined as:

$K_{s p}=\left(a_{\mathrm{Ni}^{2+}}\right)_{e q}^{1} \cdot\left(a_{s^{2-}}\right)_{e q}^{1}$

Therefore, it is possible to write:

$S=\sqrt{\frac{a_{\mathrm{Ni}^{2+}}^{1} \cdot a_{S^{2-}}^{1}}{K_{s p}}}$

Agglomeration is an important phenomenon during the precipitation of sparingly soluble compounds, such as metallic sulfides.
Agglomeration along with nucleation and growth define the particle size distribution (PSD) of the products. Assuming that the crystals have the same shape, are well-mixed in a constant volume reactor; that steady-state conditions are observed and that no crystals are present in the inlet stream, the population balance can be written as:

$\frac{\mathrm{d}\left[G_{v}(v) n(v)\right]}{\mathrm{d} v}+\frac{n(v)}{\tau}=B-D$

where $n(v)$ is the crystal population density function $\left(\# . \mu \mathrm{m}^{-3} \mathrm{~m}^{-3}\right)$ expressed as a function of the crystal the volume $v\left(\mathrm{~m}^{3}\right) ; G_{v}$ is the volumetric growth rate $\left(\mu \mathrm{m}^{3} \mathrm{~s}^{-1}\right)$ and $\tau$ is the residence time (s) $[16,17]$. The term (B - D) on the right-hand side of Eq. (5) represents the net appearance of particles of volume $v$ from two particles of volume $u$ and $v-u$, due to breakage and aggregation mechanisms. The birth $(B)$ and death $(D)$ terms can be represented by:

$B=\frac{1}{2} \int_{0}^{v} \beta(u, n-u) n(u) n(v-u) \mathrm{d} u$

$D=n(v) \int_{0}^{\infty} \beta(u, v) n(u) \mathrm{d} u$

where $\beta_{0}(u, v-u)$ is the agglomeration kernel between particles of volume $u$ and $v-u$. The agglomeration kernel represents the frequency of collisions between both particles to produce an agglomerate of volume $v$.

The agglomeration kernel is more easily determined if the PSD is analyzed by the method of moments such that the population balance equation is reduced to a set of ordinary differential equations (ODEs). The $\mathrm{j}$ moment, $\mu_{i}$, is defined as:

$\mu_{i}=\int_{0}^{\infty} \nu^{j} n(v) d u \quad j=0,1,2,3$

Assuming that both the crystal growth and the agglomeration kernel are independent of particle size, Eq. (5) can be written in terms of first three moments to produce Eqs (9)-(11) (for further details, the reader is referred to the work of Gomez-Morales et al. [18]):

$G_{v}=\frac{1}{\tau} \cdot \frac{\mu_{1}}{\mu_{0}}$

$B_{0}=\frac{1}{2 \tau}\left(\frac{\mu_{2} \mu_{0}^{2}}{\mu_{1}^{2}}\right)$

$\beta_{0}=\frac{1}{\tau}\left(\frac{\mu_{2}}{\mu_{1}^{2}}-\frac{2}{\mu_{0}}\right)$

The nuclei population density, $\mathrm{n}_{0}$, can be determined from the nucleation and growth rates as follows:

$B_{0}=n_{0} \cdot G$

\section{Materials and methods}

\subsection{Reagents and solutions}

The nickel-containing solutions were prepared from analytical grade $\mathrm{NiCl}_{2} \cdot 6 \mathrm{H}_{2} \mathrm{O}$ (Synth) dissolved in distilled water, having been previously bubbled with nitrogen gas for 15 min such that dissolved oxygen was removed. The nickel content was determined by ICP-OES, after pH adjustment. In the case of the sulfide solution, nitrogen gas was first bubbled into boiled distilled water, which was later used to prepare the solution from analytical grade $\mathrm{Na}_{2}$ $\mathrm{S} \cdot 9 \mathrm{H}_{2} \mathrm{O}$ (Synth). A series of experiments was carried out with the effluent of a continuous sulfate reduction bioreactor, type UASB, operating at hydraulic time retention (HTR) of $24 \mathrm{~h}, \mathrm{COD}: \mathrm{SO}_{4}{ }^{2-}$ ratio at 1.8 , treating $2.0 \mathrm{~g} \mathrm{~L}^{-1}$ sulfate in the presence of lactate as 
electron and carbon source and [19]. As received, the solution with $\mathrm{pH}$ value at 7.6 and had the sulfide content determined prior to mixing with the $\mathrm{Ni}^{2+}$ solution. The analysis encompassed the precipitation of the sulfide by mixing the effluent of the sulfate reduction bioreactor with zinc acetate (Aldrich). The precipitate was washed to remove impurities and was transferred to an Erlenmeyer flask, where the precipitate reacted with an excess of iodine (Merck) in an acid medium. The remaining iodine was subsequently determined by titration with sodium thiosulfate (Aldrich) using starch as the indicator [20]. In addition to sulfide ions, the effluent of the sulfate reduction bioreactor also contained acetate $\left(\sim 2000 \mathrm{mg} \mathrm{L}^{-1}\right)$, alkalinity $\left(\sim 1000 \mathrm{mg} \mathrm{L}^{-1}\right)$ and phosphate ions (110 $\mathrm{mg} \mathrm{L}^{-1}$ as $\mathrm{P}$ ). The $\mathrm{pH}$ adjustments in the Ni solutions were made with hydrochloric acid (Synth) solution $\left(10 \%, v^{-1} \mathrm{v}^{-1}\right)$ or sodium hydroxide (Synth), 10\% (w.v $\left.{ }^{-1}\right)$. For $\mathrm{pH}$ measurements, the pH meter Handylab 1, from Schott ${ }^{\circledR}$, was utilized.

\subsection{Batch precipitation experiments with either $\mathrm{Na}_{2} \mathrm{~S}$ or biogenic sulfide}

Preliminary experiments were carried out to investigate the effects of $\mathrm{pH}$ and time on nickel sulfide precipitation. These experiments were carried out in a $1000 \mathrm{~mL}$ Erlenmeyer flask with magnetic stirring (IKA Labortechnik) in a fume hood. To the Erlenmeyer flask, a volume of $400 \mathrm{~mL}$ of a $500 \mathrm{mg} \mathrm{L}^{-1} \mathrm{Ni}^{2+}$ solution, at $\mathrm{pH}$ values of 3,5 or 7 (initial values), and the same volume of a solution containing stoichiometric sulfide concentrations (at $\mathrm{pH}$ 12.0) were mixed at time zero. The effect of supersaturation on nickel precipitation was also investigated by varying the nickel concentration such that a $1\left[\mathrm{Ni}^{2+}\right]: 1.5\left[\mathrm{~S}^{2-}\right]$ molar ratio inside the reactor was achieved.

Experiments were also carried out with biogenic sulfide, and the experimental conditions were the same as previously reported but with different nickel and sulfide content. Because the measured sulfide concentration in the effluent of the sulfate reduction bioreactor was $98 \mathrm{mg} \mathrm{L}^{-1}$, the nickel content was set at $172.1 \mathrm{mg} \mathrm{L}^{-1}$ and $90.7 \mathrm{mg} \mathrm{L}^{-1}$ in the experiments with stoichiometric and excess sulfide, respectively.

The batch experiment ran for $20 \mathrm{~min}$, and samples were collected every $2 \mathrm{~min}$ for the first $10 \mathrm{~min}$. The samples that had been collected were filtered using polyethylene filter units (HV Durapore ${ }^{\circledR}$ membrane, $0.45 \mu \mathrm{m}$ ) attached to $10-\mathrm{mL}$ syringes. The working sample volume was $10 \mathrm{~mL}$. A drop of concentrated $\mathrm{HNO}_{3}$ (Aldrich) was used to preserve the filtered samples (aqueous phase) for subsequent quantitative analysis ( $\mathrm{Ni}$ and $S_{\text {total }}$ ) by ICPOES (725 Varian). The $\mathrm{pH}$ inside the reactor was determined by a Handylab $1 \mathrm{pH}$ meter from Schott.

\subsection{Nickel precipitation in a continuous system (with either Na2S or biogenic sulfide)}

To investigate nickel precipitation in continuous systems, an unbaffled MSMPR reactor with a working volume of $300 \mathrm{~mL}$ (132 $\mathrm{mm}$ height and $67 \mathrm{~mm}$ diameter), as sketched in Fig. 1, was utilized. Two different solutions, one containing nickel and the other, sodium sulfide, were pumped separately into the reactor by peristaltic pumps $\left(\operatorname{Milan}^{\circledR}\right)$. The flow rate was set at $15 \mathrm{~mL} \mathrm{~min}^{-1}$ in each pump such that the residence time was $10 \mathrm{~min}$. The nickel solutions were prepared with initial $\mathrm{pH}$ values of 3, 5 and 7 and a concentration of $500 \mathrm{mg} \mathrm{L}^{-1} \mathrm{Ni}$. The anionic solution, at its natural $\mathrm{pH}$ (12.2), contained $275 \mathrm{mg} \mathrm{L}^{-1} \mathrm{~S}^{2-}$ such that a $1\left[\mathrm{Ni}^{2+}\right]: 1\left[\mathrm{~S}^{2-}\right]$ molar ratio was attained. All tests were carried out at room temperature $\left(22 \pm 2{ }^{\circ} \mathrm{C}\right)$, and the experiments were run for 10 residence times. In addition to the influence of $\mathrm{pH}$ on nickel removal, an experiment was performed where the metal/sulfide molar ratio was varied; therefore, the supersatura-

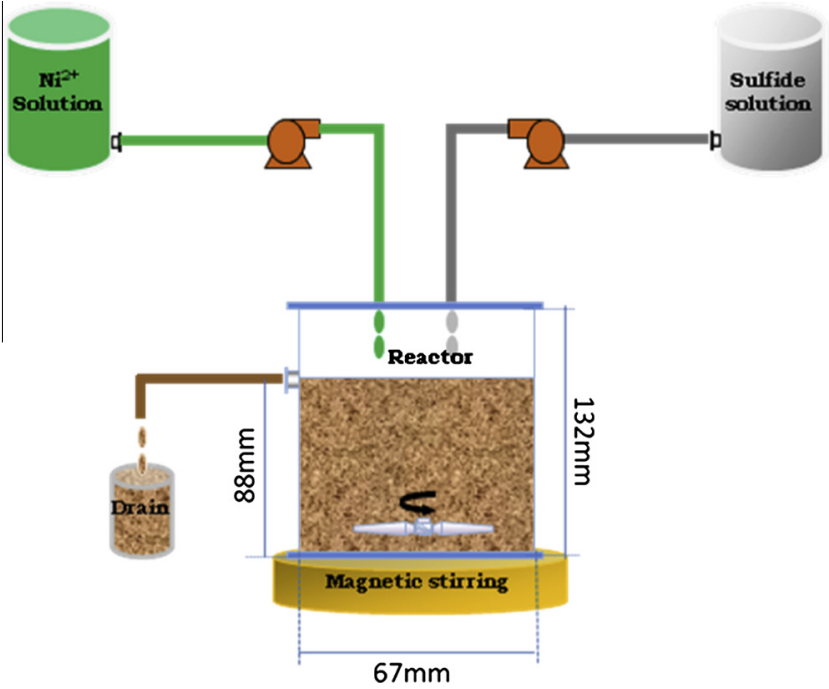

Fig. 1. Schematic representation continuous experiments.

tion of the system was also varied. In this latter case, the initial $\mathrm{pH}$ of the nickel solution was set at 3 , and the concentration of the sulfide ion was $415 \mathrm{mg} \mathrm{L}^{-1}$, corresponding to a $1\left[\mathrm{Ni}^{2+}\right]: 1.5\left[\mathrm{~S}^{2-}\right]$ molar ratio. The same experiment was also carried out with biogenic sulfide $\left(109 \mathrm{mg} \mathrm{L}^{-1}\right)$ and nickel $\left(200 \mathrm{mg} \mathrm{L}^{-1}\right)$ at the initial $\mathrm{pH}$ value of 5.0 .

Unless otherwise stated, a $25-\mathrm{mL}$ sample was collected from the reactor outlet at every residence time for a total of 10 samples. These samples were filtered using a polyethylene filter unit (HV Durapore ${ }^{\circledR}$ membrane, $0.45 \mu \mathrm{m}$ ) attached to a 10 -mL syringe, and the metal precipitation efficiency was determined from the amount of metal remaining in solution after precipitation. Similarly to the batch experiments, $\mathrm{HNO}_{3}$ was utilized to oxidize the sulfide and interrupt precipitation. Nickel and total sulfur were analyzed by ICP-OES (Varian 725). This latter measurement was assumed to represent all sulfide in solution in the experiments with sodium sulfide, whereas titration with iodine (Section 3.1) was utilized for sulfide determination in the testing with biogenic sulfide. X-ray diffraction (Shima$\mathrm{dzu}^{\circledR}$ XRD6000) was applied to identify the phases formed with optical microscopy (Leica) utilized for crystal form.

\subsection{Modeling the precipitation kinetics}

The kinetic modeling was performed from the PSD produced in the continuous experiments. After the system reached steady-state conditions, a volume of $300 \mathrm{~mL}$ of slurry leaving the reactor was collected and filtered, and the solid mass was determined such that the percentage of solids in the slurry (magma density) was known. The solid phase was kept under a nitrogen atmosphere until the moment of measurement of PSD. The PSD was determined by a laser particle size analyzer (Cilas ${ }^{\circledR}$ model 1064). The mass of one crystal was determined from the shape factor (assuming spherical particles) and particle density (helium pycnometry) for each size fraction determined in the PSD. The number of crystals $\left(n_{0}\right)$ was thus calculated from the mass retained in each size fraction, and nucleation and growth rates were subsequently determined.

\section{Results and discussion}

\subsection{Batch nickel precipitation with either sodium sulfide or biogenic sulfide}

Preliminary experiments were carried out by mixing nickel chloride and sodium sulfide solutions to define the values of both 
the initial $\mathrm{pH}$ and reaction time that ensured an efficient nickel precipitation. The initial $\mathrm{pH}$ values of the nickel chloride solution were defined following the studies of Bijmans et al. [1] and Tokuda et al. [2].

Fig. 2a shows the profile of the nickel concentration, and Fig. 2b depicts the $\mathrm{pH}$ variation during the batch experiments. Within 10 min, nickel precipitation was almost complete, regardless of the initial $\mathrm{pH}$ of the nickel solution. The $\mathrm{pH}$ of the nickel solution increased to approximately 9.0 as mixing with the sulfide solution occurred, which was consistent with the results produced under similar experimental conditions [14]. Higher values of the initial $\mathrm{pH}$ improved nickel removal, with the $\mathrm{pH}$ value of 7 producing the lowest residual metal concentrations $\left(0 \mathrm{mg} \mathrm{L}^{-1}\right.$, within $10 \mathrm{~min}$ ). This finding is consistent with those of Karbanee et al. [14] and Sampaio et al. [15], who stated that nickel precipitation by sodium sulfide is strongly influenced by $\mathrm{pH}$. A tendency toward dissolution of the precipitated sulfide was also observed, as long as the experimental time was longer than $20 \mathrm{~min}$. This tendency is probably derived from the low stability of the finer NiS particles. The largest residual nickel concentration was $0.7 \mathrm{mg} \mathrm{L}^{-1}$ (initial $\mathrm{pH} 3$ ) within 10 min of testing, which complies with most environmental regulations [21].

Similar experiments were performed with the biogenic sulfide produced in the sulfate reduction bioreactor. As this solution presented a sulfide content of $98 \mathrm{mg} \mathrm{L}^{-1}$, precipitation experiments were carried out with solutions containing $190 \mathrm{mg} \mathrm{L}^{-1} \mathrm{Ni}^{2+}$ at the same $\mathrm{pH}$ values employed in the experiments with sodium sulfide (either 3,5 or 7 ). The condition of $50 \%$ excess sulfide, which was not assessed in the batch experiments with sodium sulfide, was also tested with the initial nickel concentration reduced to
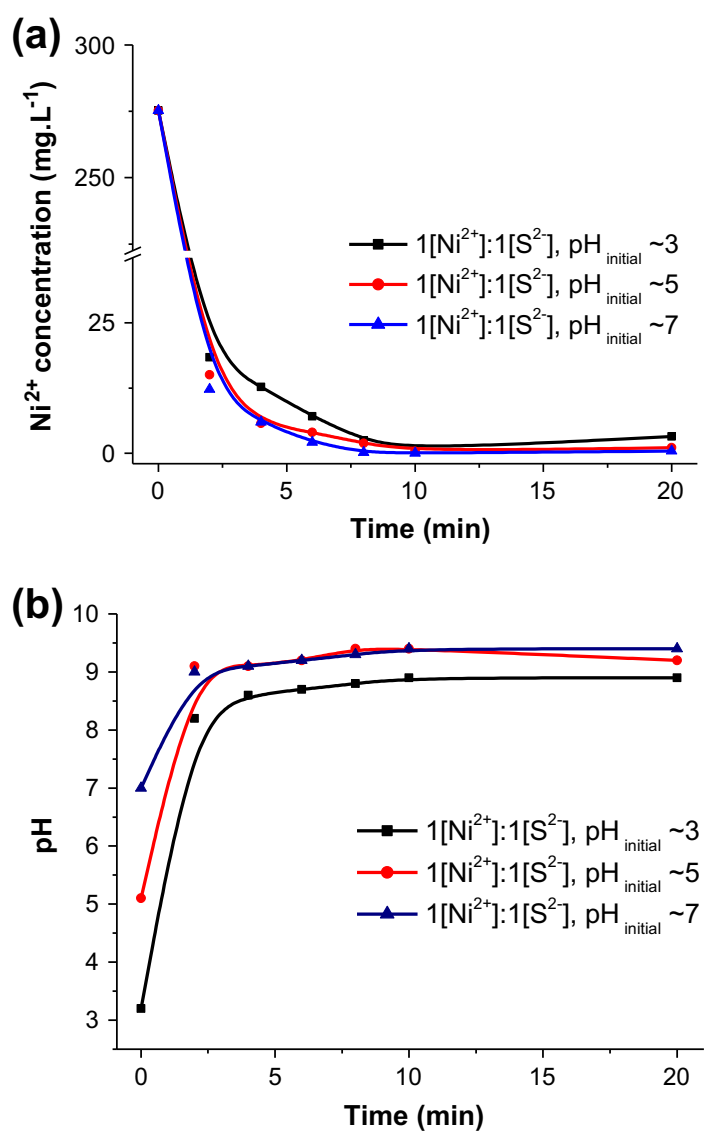

Fig. 2. Profile of metal concentration (a) and $\mathrm{pH}$ (b) during nickel precipitation with sodium sulfide in batch experiments, at $22 \pm 2{ }^{\circ} \mathrm{C}$.
$90.7 \mathrm{mg} \mathrm{L}^{-1}$. The results achieved for each experimental condition are shown in Table 1. Nickel removal with biogenic sulfide was not so efficient at lower initial $\mathrm{pH}$ values ( $\mathrm{pH}$ 3), which is similar to the results observed with sodium sulfide. However, the residual nickel concentration was as high as $46.5 \mathrm{mg} \mathrm{L}^{-1}$. The $\mathrm{pH}$ value of 5 (initial $\mathrm{pH}$ of the nickel solution) was the most effective because the residual metal concentration was $0.09 \mathrm{mg} \mathrm{L}^{-1}$. This observation corroborates the work of Bijmans et al. [1], who observed complete removal at $\mathrm{pH}$ values above 5 . In Table 1 , for the initial $\mathrm{pH}$ values of 7.0, the residual nickel concentration also reached values below $1 \mathrm{mg} \mathrm{L}^{-1}$, complying with most environmental regulations [21]. Notwithstanding, the residual sulfide concentration was not consistent with nickel sulfide formation, indicating that under these conditions, nickel was removed as a different compound. The precipitates produced with the effluent of the sulfate reduction reactor were thus analyzed by X-ray diffraction (XRD) (Fig. 3). From the analysis of the XRD data for the precipitate produced at $1\left[\mathrm{Ni}^{2+}\right]: 1\left[\mathrm{~S}^{2-}\right]$ and $\mathrm{pH}_{\text {initial }} \sim 7$, it was concluded that the metal was precipitated as nickel ammonium phosphate hexahydrate $\left(\mathrm{NiNH}_{4} \mathrm{PO}_{4} \cdot 6 \mathrm{H}_{2} \mathrm{O}\right)$ and not as sulfide, which explains the residual sulfide concentration value of $85.66 \mathrm{mg} \mathrm{L}^{-1}$ for a metal removal efficiency of $99.87 \%$. The presence of phosphate and ammonium ions in the effluent of the sulfate reduction bioreactor was due to the nutrients used for the growth of sulfate-reducing bacteria. For the other conditions tested, the solid phase appeared to be amorphous and could not be identified by X-ray diffraction, which was a feature also reported by Sampaio e al. [22]. Esposito et al. [23] also observed the interference of other species, such as phosphate and carbonate, present in the biogenic sulfide solution when these authors studied the precipitation of zinc with biogenic sulfide.

\subsection{Continuous nickel precipitation with either sodium sulfide or biogenic sulfide}

After the batch precipitation studies, a series of continuous experiments was carried out in which the initial $\mathrm{pH}$ of the nickel solution and the effect of the $\left[\mathrm{Ni}^{2+}\right]:\left[\mathrm{S}^{2-}\right]$ molar ratio on nickel sulfide precipitation were investigated. Fig. 4 shows the profiles of both metal concentration and supersaturation during such experiments. From the analysis of the residual metal concentration, the best results were achieved for the stoichiometric ratio between the metal and sulfide ions, as observed in the batch experiments, which was consistent with the results obtained by Karbanee et al. [14] during continuous nickel sulfide precipitation. The experiments performed at $\mathrm{pH} 9.5$ (initial $\mathrm{pH}$ of the nickel solution set at 5) and 10.5 (initial $\mathrm{pH}$ at 7), respectively, demonstrated that nickel removal from solution attained $99.8 \%$, which was equivalent to $0.51 \mathrm{mg} \mathrm{L}^{-1}$ residual $\mathrm{Ni}^{2+}$ concentration. Such figures were observed in the seventh and sixth residence times, respectively. The testing performed at an initial $\mathrm{pH}$ value of 3 ( 8.5 inside the reactor) showed a residual nickel concentration above the limit set by environmental legislation [21]. Under such experimental condition, the residual nickel content remained above $3 \mathrm{mg} \mathrm{L}^{-1}$ throughout the test, which was in agreement with the results reported by Lewis and van Hille [12]. The experiment with excess sulfide did not improve nickel removal because the residual metal concentration was always above $6 \mathrm{mg} \mathrm{L}^{-1}$ (Fig. 4a), which was equivalent to a nickel removal efficiency of only $97 \%$. Karbanee et al. [14] also reported that at $\left[\mathrm{Ni}^{2+}\right]:\left[\mathrm{S}^{2-}\right]=1: 1.5$, the $\mathrm{pH}$ value inside the reactor was 11.5 , and nickel removal was only $70 \%$. The authors proposed that the excess sulfide produced nickel-sulfide complexes (stable at $\mathrm{pH}$ values above 7), which accounted for metal redissolution.

Fig. 5 presents the XRD patterns for the nickel sulfide precipitated in the continuous experiments. Potential nickel sulfide phases include $\alpha$-NiS, $\beta-\mathrm{NiS}, \mathrm{NiS}_{2}$ (vaesite), $\mathrm{Ni}_{3} \mathrm{~S}_{4}$ (polydymite), 
Table 1

Nickel precipitation by biogenic sulfide in batch conditions. Initial sulfide concentration: $98 \mathrm{mg} \mathrm{L}^{-1}$.

\begin{tabular}{|c|c|c|c|c|c|c|}
\hline Initial $\mathrm{pH}$ & {$\left[\mathrm{Ni}^{2+}\right]:\left[\mathrm{S}^{2-}\right]$ ratio } & Final $\mathrm{pH}$ & {$\left[\mathrm{Ni}^{2+}\right]_{\text {initial }}\left(\mathrm{mg} \mathrm{L}^{-1}\right)$} & {$\left[\mathrm{Ni}^{2+}\right]_{\text {residual }}\left(\mathrm{mg} \mathrm{L}^{-1}\right)$} & {$\left[\mathrm{S}^{2-}\right]_{\text {residual }}\left(\mathrm{mg} \mathrm{L}^{-1}\right)$} & Removal (\%) \\
\hline 3.0 & $1: 1$ & 7.3 & 172.1 & 46.50 & 15.96 & 72.98 \\
\hline 5.0 & $1: 1$ & 9.4 & 172.1 & 0.09 & 0.00 & 99.95 \\
\hline 7.0 & $1: 1$ & 10.7 & 172.1 & 0.23 & 85.66 & 99.87 \\
\hline 3.0 & $1: 1.5$ & 5.2 & 90.7 & 3.26 & 43.82 & 96.41 \\
\hline
\end{tabular}

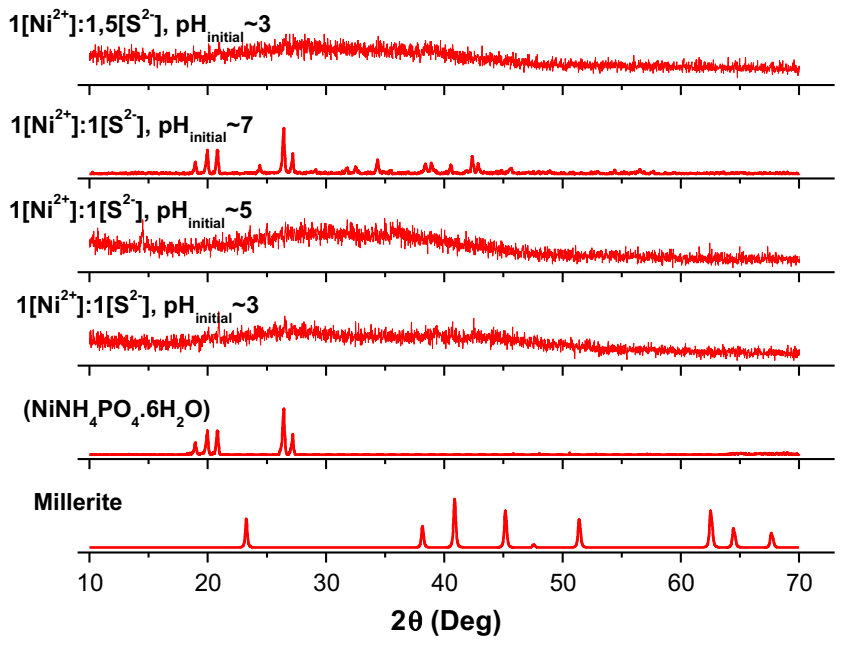

Fig. 3. X-ray diffraction results for nickel precipitation by biogenic sulfide along with Millerite and nickel ammonium phosphate hexahydrate spectra.

(a)
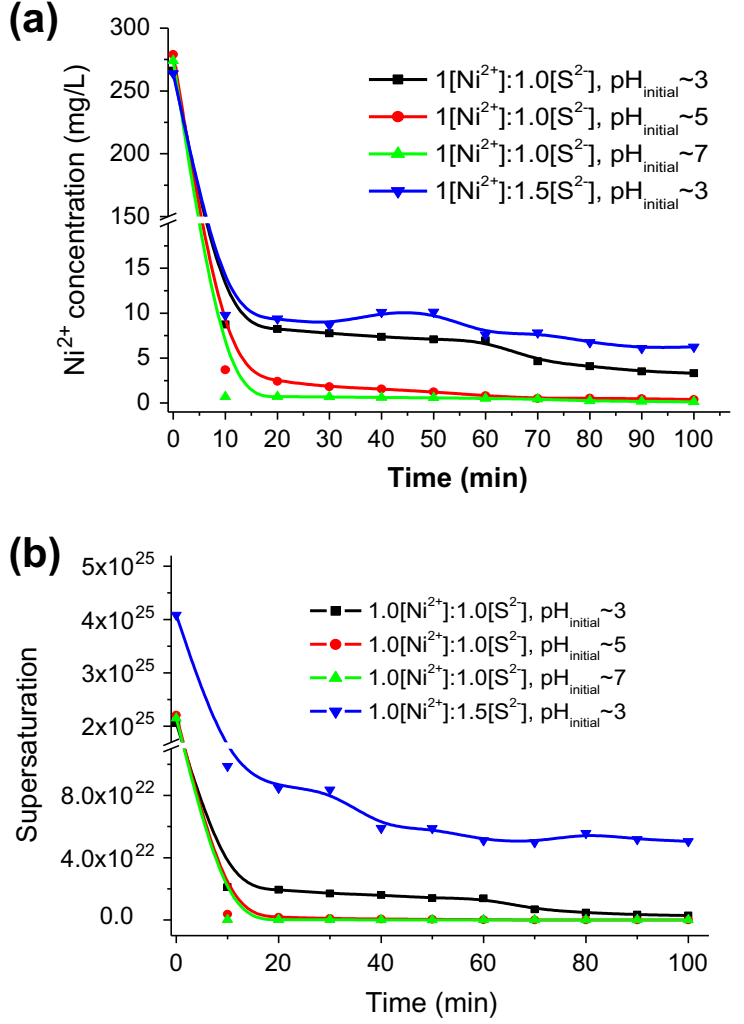

Fig. 4. Profiles of nickel concentration (a) and supersaturation (b) during continuous precipitation of nickel at different initial $\mathrm{pH}$ values and $\left[\mathrm{Ni}^{2+}\right]:\left[\mathrm{S}^{2-}\right]$ ratios. Residence time: $10 \mathrm{~min}$ and $22 \pm 2{ }^{\circ} \mathrm{C}$.

although $\alpha$-NiS was proposed as the only phase formed in the 25$60{ }^{\circ} \mathrm{C}$ range, under fully anaerobic conditions (precipitation was carried out in a glove box). The X-ray diffraction pattern presented

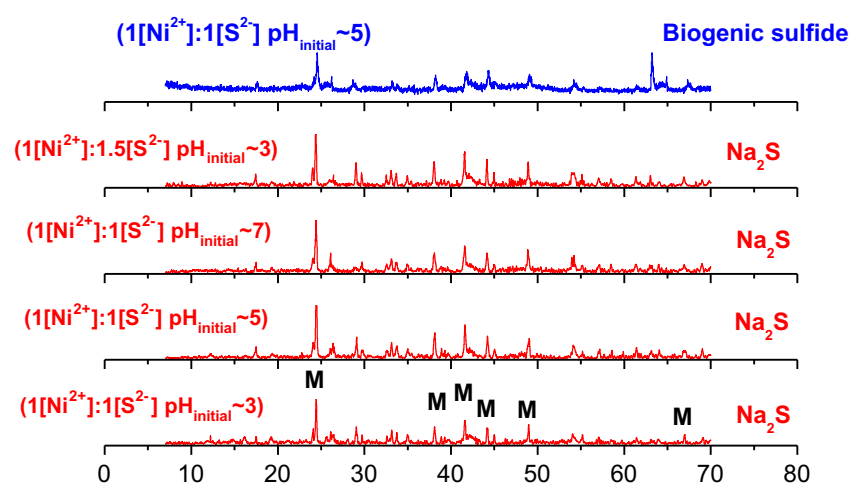

Fig. 5. X-ray diffraction patterns of nickel sulfide precipitated in continuous system with both $\mathrm{Na}_{2} \mathrm{~S}$ and biogenic sulfide.

in Fig. 5 suggested millerite as the compound closest to the precipitates produced, as also observed by Sampaio et al. [15].

Continuous nickel precipitation with biogenic sulfide was assessed next, and the results are presented in Fig. 6. It could be observed that both the $\mathrm{pH}$ of the reaction medium and the metal removal efficiency remained stable at $8.5 \%$ and $99.9 \%$, respectively, from $40 \mathrm{~min}$ (four residence times) onward with a residual level of $0.25 \mathrm{mg} \mathrm{L}^{-1} \mathrm{Ni}^{2+}$. Bijmans et al. [1] studied nickel sulfide precipitation and observed a removal efficiency of $99.6 \%$, with a residual nickel content of $0.4 \mathrm{mg} \mathrm{L}^{-1}$.

XRD data for the nickel precipitated with biogenic sulfide in the continuous process are shown in Fig. 5. Unlike the batch precipitation experiments in which the precipitates did not show a high degree of crystallinity (as suggested by the shoulder in the baseline of Fig. 3), the products of continuous precipitation were crystalline. Millerite (NiS) is the solid phase precipitated with biogenic sulfide, in agreement with the findings of Bijmans et al. [1], whereas ammonium nickel phosphate, identified in the batch tests, was not observed.

\subsection{Modeling the kinetics of continuous nickel sulfide precipitation}

The well-mixed reactor is not the most appropriate technique for studying fast precipitation reactions because of mass transfer control and high supersaturations. Despite such a disadvantage, the well-mixed reactor was applied to study the precipitation of a series of sparingly soluble compounds, such as hydroxyapatite [18], calcium carbonate [24] and copper and zinc sulfides [25]. Additionally, other reactors could not avoid the effect of high supersaturation [13].

Precipitation modeling was carried out only with the results of the continuous precipitation experiments with sodium sulfide because attempts to assess the PSD of the solid particles produced with biogenic sulfide were not successful, due to the high reactivity of the fine precipitates. From PSD magma density and particle density, the number of particles in each fraction was determined, assuming a volume shape factor equal to $\pi / 6$.

The PSDs were determined in a laser particle size analyzer, and the results are shown in Fig. 7. For the stoichiometric condition 


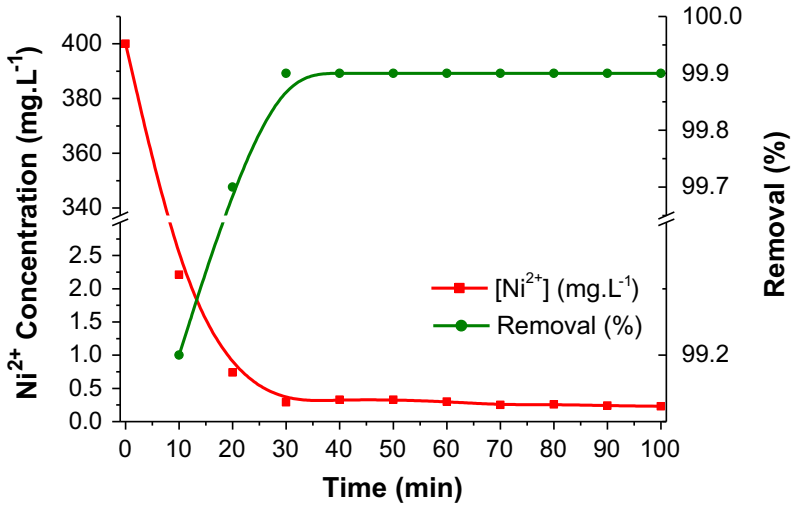

Fig. 6. Metal concentration and removal efficiencies determined during $\mathrm{NiS}$ precipitation with biogenic sulfide. Stoichiometric ratio between nickel and sulfide, $\mathrm{pH}_{\mathrm{i}}=5$; 10-min residence time; temperature: $22 \pm 2{ }^{\circ} \mathrm{C}$
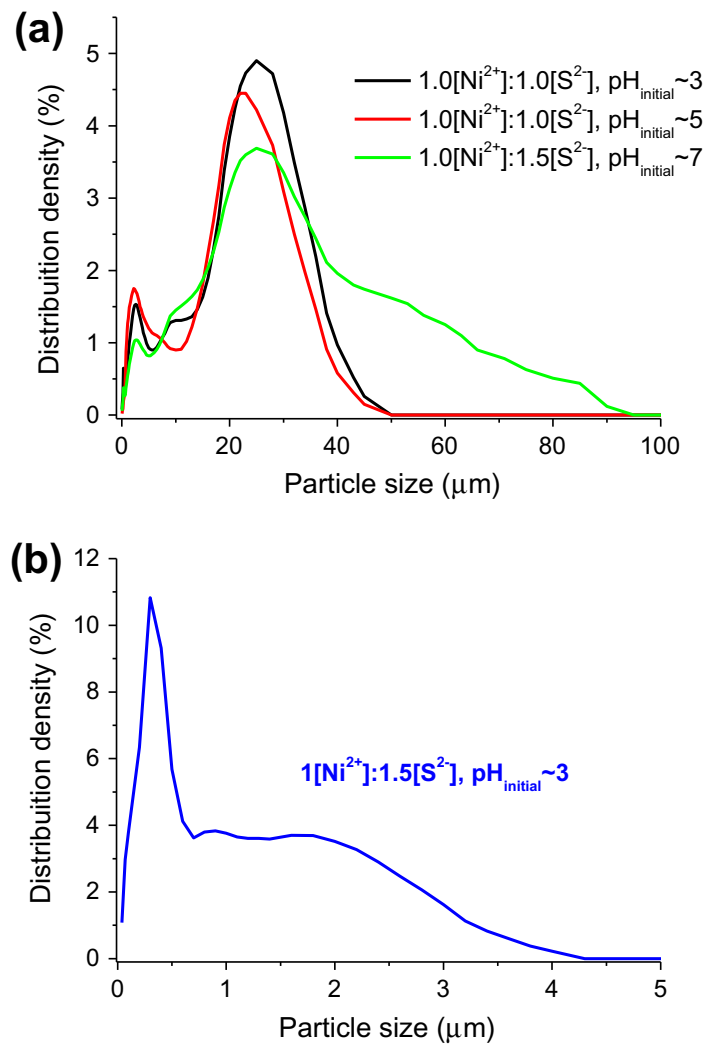

Fig. 7. Particle size distributions of nickel sulfide precipitated in continuous systems at different initial $\mathrm{pH}$ values (a) and $\left[\mathrm{Ni}^{2+}\right]:\left[\mathrm{S}^{2-}\right]$ ratios (b).

(Fig. 7a), the $d_{50}$ values were approximately $7.6 \mu \mathrm{m}$ and $9.8 \mu \mathrm{m}$ for the initial $\mathrm{pH}$ values of 3 and 5, respectively, and both PSDs were similar. For the initial $\mathrm{pH}$ value of 7 , the PSD was broader, with $d_{50}$ and $d_{90}$ values of $23.1 \mu \mathrm{m}$ and $70.6 \mu \mathrm{m}$, respectively, being observed (Fig. 7a). Such results are consistent with the values observed during zinc sulfide precipitation [15]. Supersaturation values (measured at steady state, Table 2) were consistent with the values reported by Lewis and Swartbooi [13], who investigated nickel precipitation in fluidized bed reactors. Considering the stoichiometric ratio between metal and sulfide and initial $\mathrm{pH}$ of 3 , the value of supersaturation at steady state was $8.23 \times 10^{10}$. With excess sulfide $\left(1\left[\mathrm{Ni}^{2+}\right]: 1.5\left[\mathrm{~S}^{2-}\right]\right)$, supersaturation attained a value of $2.23 \times 10^{11}$, whereas the average particle size was reduced to $0.27 \mu \mathrm{m}$ (Fig. $7 \mathrm{~b})$.
As shown in Fig. 8, the logarithm of the population density function $(\operatorname{Ln} n)$ was not a linear function of particle volume, which implies that nucleation and growth were not the only precipitation mechanisms [17]. The concavity observed suggests that aggregation is occurring with the number of large particles increasing at the expense of smaller crystals, which is relatively common during precipitation of metallic sulfides [18]. The PSD at steady state allowed to determine the agglomeration kernel from the population balance in volume coordinates and assuming size-independent agglomeration [18].

Eqs. (8)-(11) were applied to assess the values of both the growth and nucleation rate and the agglomeration kernel. From the former, the concentration of nuclei $\left(n_{0}\right)$ was also determined using Eq. (12). To calculate the kernel, the log of population density was fitted to an empirical equation (in which $P_{1}, P_{2}$ and $P_{3}$ are fitting parameters) presented by Tai and Chen [24] and converted to a volume base, assuming spherical particles.

$\operatorname{Ln} n(v)=P_{1} \exp \left[\mathrm{P}_{2}\left(\frac{6 * v}{\pi}\right)^{\frac{1}{3}}+\mathrm{P}_{3}\left(\frac{6 * v}{\pi}\right)^{\frac{1}{6}}\right]$

Fitting of Eq. (13) to the population density is presented in Fig. 8, while the main kinetics parameters are depicted in Table 2. According to the modeled data, the kinetics of nickel sulfide precipitation show the lowest nucleation rate $\left(B_{0}\right)$ at $8.16 \times 10^{18}$ crystals $^{-3} \mathrm{~s}^{-1}$ and the highest volumetric growth rate $\left(G_{v}\right)$ of $1.03 \times 10^{1} \mu \mathrm{m}^{3} \mathrm{~s}^{-1}$. These kinetic data imply that the better conditions for the precipitation of the metal with sodium sulfide occur at pH 7.0. As expected, both the largest growth rate and the lowest nucleation rate were observed at the lowest measured supersaturation $\left(\mathrm{pH}_{i}=7.0\right)$. Under the other conditions in which stoichiometric concentrations of nickel and sulfide were investigated, the volumetric growth rate was two orders of magnitude smaller, and the nucleation rate was larger, particularly at an initial $\mathrm{pH}$ of 3 , where supersaturation was higher $\left(8.23 \times 10^{10}\right)$. With the increase in the $[\mathrm{Ni}]:[\mathrm{S}]$ ratio to $1: 1.5$, supersaturation also increased to $2.23 \times 10^{11}$, resulting in the largest nucleation rate $\left(3.91 \times 10^{20}\right)$ and thus the smallest volumetric growth rate $\left(1.36 \times 10^{-4} \mu \mathrm{m}^{3} \mathrm{~s}^{-1}\right)$. The nuclei concentration $\left(n_{0}\right)$ followed the same trend and increased with supersaturation, as expected. In studies carried out by Al-Tarazi et al. [8], which investigated $\mathrm{ZnS}$ precipitation, supersaturation varied between $1 \times 10^{8}$ and $5 \times 10^{10}$ and nucleation rates values from $10^{9}$ to $10^{15}$ nuclei $\mathrm{m}^{-3} \mathrm{~s}^{-1}$ were observed.

The agglomeration kernel $\left(\beta_{0}\right)$ varies with supersaturation and nucleation in a complex manner. Generally, the agglomeration kernel increases with the primary nucleation rate while decreasing with either the volumetric growth rate or supersaturation. At $1[\mathrm{Ni}]: 1[\mathrm{~S}]$, the agglomeration kernel decreased with the nucleation rate (i.e., $\mathrm{pH}$ ), but increased when the growth rate was reduced. $\mathrm{Al}$ Tarazi et al. [8] reported similar behavior for both growth and nucleation rates, although the agglomeration kernel increased with $\mathrm{pH}$. The increase in the agglomeration kernel with $\mathrm{pH}$, however, leveled out for the experiments carried out at higher $\mathrm{pH}$ (6.0). When two different level of supersaturation were herein compared, the higher supersaturation implied a lower value of the agglomeration kernel, as expected [8], probably because higher sulfide concentrations caused a reduction in zeta potential of the solid particles (the surface charge became more negative) due to the sorption of sulfide ions [26]. Repulsion among different particles was therefore stronger, resulting in smaller particles and the lowest growth rate and agglomeration kernel values depicted in Table 2.

Despite intense research, technologies for bioreduction of sulfate (active treatment) have encountered intense competition with other sulfate removal approaches, such as ultrafiltration and reverse osmosis [27]. The principal reason seems to be availability 
Table 2

Kinetic data for continuous nickel precipitation. Inlet sulfide concentration: $250 \mathrm{mg} \mathrm{L}^{-1}$.

\begin{tabular}{|c|c|c|c|c|c|c|}
\hline Experimental condition & Supersaturation & $\mathrm{pH}^{\mathrm{a}}$ & $n_{0}\left(\# . \mu \mathrm{m}^{-3} \mathrm{~m}^{-3}\right)$ & $\beta_{0}\left(\mathrm{~m}^{3} . \#^{-1} \mathrm{~s}^{-1}\right)$ & $G_{v}\left(\mu \mathrm{m}^{3} \mathrm{~s}^{-1}\right)$ & $B_{0}\left(\# \cdot \mathrm{m}^{-3} \mathrm{~s}^{-1}\right)$ \\
\hline $\begin{array}{l}1\left[\mathrm{Ni}^{2+}\right]: 1\left[\mathrm{~S}^{2-}\right] \\
\mathrm{pH}_{i} \sim 3\end{array}$ & $8.23 E+10$ & 8.7 & $1.14 \mathrm{E}+20$ & $2.31 \mathrm{E}-22$ & $4.58 \mathrm{E}-01$ & $5.20 \mathrm{E}+19$ \\
\hline $\begin{array}{l}1\left[\mathrm{Ni}^{2+}\right]: 1\left[\mathrm{~S}^{2-}\right] \\
\mathrm{pH}_{i} \sim 5\end{array}$ & $7.55 E+09$ & 9.4 & $1.88 \mathrm{E}+20$ & $2.44 \mathrm{E}-22$ & $3.42 \mathrm{E}-01$ & $6.43 E+19$ \\
\hline $\begin{array}{l}1\left[\mathrm{Ni}^{2+}\right]: 1\left[\mathrm{~S}^{2-}\right] \\
\mathrm{pH}_{i} \sim 7\end{array}$ & $6.93 E+09$ & 10.8 & $7.94 \mathrm{E}+17$ & $9.71 \mathrm{E}-23$ & $1.03 \mathrm{E}+01$ & $8.16 \mathrm{E}+18$ \\
\hline $\begin{array}{l}1\left[\mathrm{Ni}^{2+}\right]: 1.5\left[\mathrm{~S}^{2-}\right] \\
\mathrm{pH}_{i} \sim 3\end{array}$ & $2.23 \mathrm{E}+11$ & 11.6 & $2.88 \mathrm{E}+24$ & $2.39 \mathrm{E}-23$ & $1.36 \mathrm{E}-04$ & $3.91 \mathrm{E}+20$ \\
\hline
\end{tabular}

a $\mathrm{pH}$ of the reaction medium. Supersaturation and $\mathrm{pH}$ values determined at steady state.
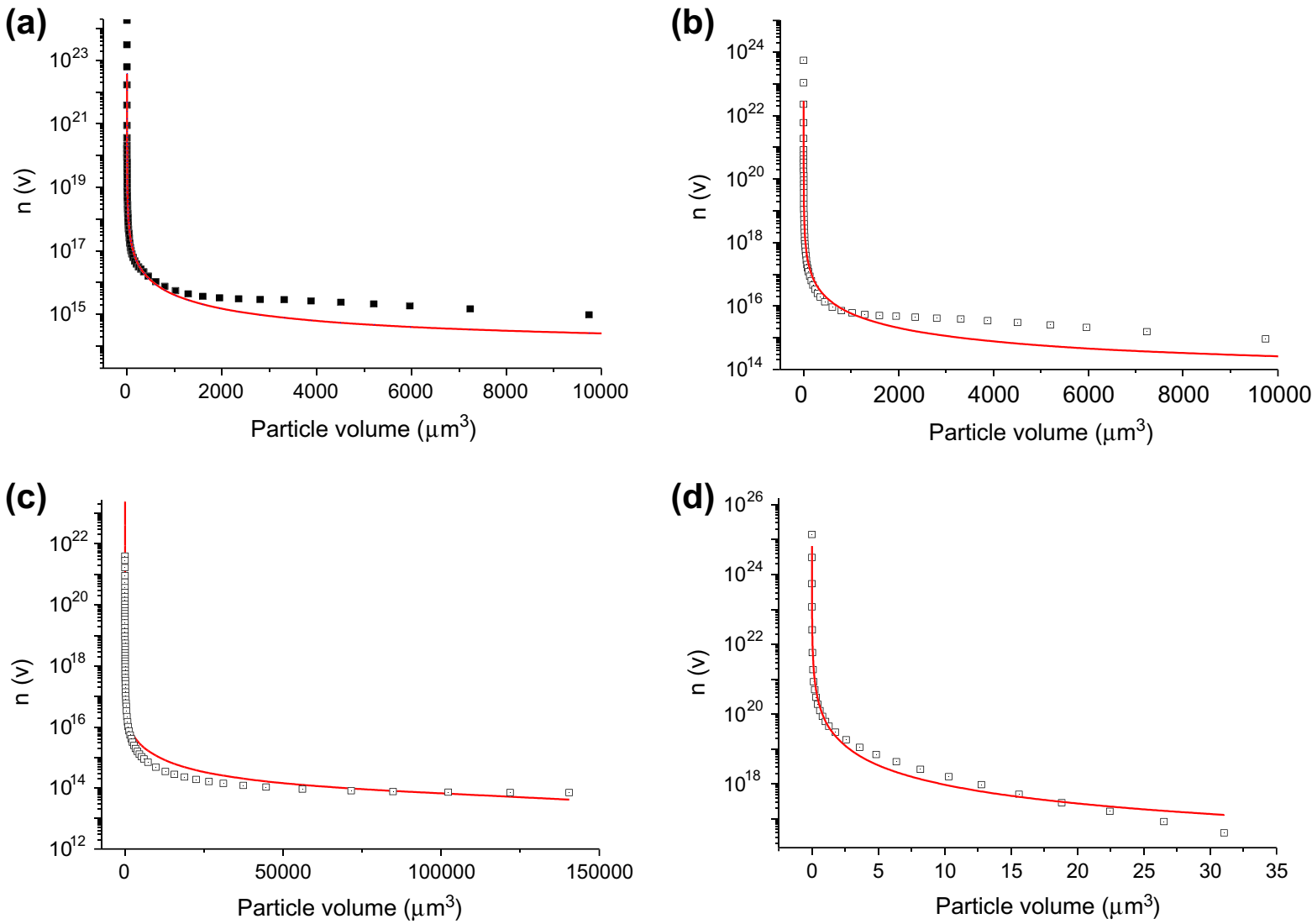

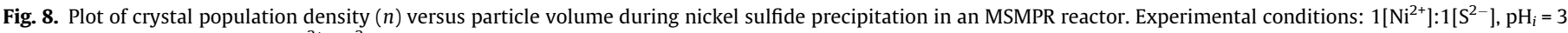
(a), $\mathrm{pH}_{i}=5$ (b) and $\mathrm{pH}_{i}=7$ (c); $\left.\mathrm{Ni}^{2+}\right]:\left[\mathrm{S}^{2-}\right]$ molar ratio of $1: 1.5$ and initial $\mathrm{pH} 3$ (d).

and costs of organic matter (the carbon and electron donor) and thus few industrial projects have been commissioned [28] for sulfate removal. On-site sulfide production has, however, gained widespread acceptance for metal recovery from industrial effluents and mine drainage [29], not to mention projects in which chemical sulfide is applied for nickel recovery with either an environmental [29] or hydrometallurgical perspective [30]. Notwithstanding and irrespective of the source of sulfide, metallic sulfide precipitation has many challenges. Supersaturation particularly should be controlled such that formation of fine precipitates is minimized. Further research is needed to address these issues.

\section{Conclusions}

Sodium sulfide can be applied successfully for the precipitation of nickel in the form of metal sulfide, as residual levels equal to $0.13 \mathrm{mg} \mathrm{L}^{-1}$ were obtained for the continuous tests performed with the stoichiometric ratio between metal and sulfide. This technology can be applied to industrial wastewater treatment because the residual level of nickel is below those established by environmental legislation. The largest growth rate was observed at the initial $\mathrm{pH}$ of 7 , whereas increased supersaturations impaired both crystal growth and agglomeration.

The application of biogenic sulfide in the stoichiometric amount allowed the precipitation of nickel (at initial $\mathrm{pH}$ values above 5), also to levels below the limit prescribed by environmental legislation. Nickel removal is influenced by the composition of the solution containing the biogenic sulfide and the $\mathrm{pH}$ of the medium, and precipitation may occur in the form of other compounds, such as phosphate.

\section{Acknowledgments}

Financial support from the funding agencies FINEP, FAPEMIG CNPq and CAPES is greatly appreciated. The "Conselho Nacional de Pesquisas" - CNPq scholarships to F.D. Reis and V.A. Leão are particularly acknowledged. 


\section{References}

[1] M.F.M. Bijmans, P.-J. van Helvoort, S.A. Dar, M. Dopson, P.N.L. Lens, C.J.N. Buisman, Selective recovery of nickel over iron from a nickel iron solution using microbial sulfate reduction in a gas-lift bioreactor, Water Res. 43 (2009) 853-861.

[2] H. Tokuda, D. Kuchar, N. Mihara, M. Kubota, H. Matsuda, T. Fukuta, Study on reaction kinetics and selective precipitation of $\mathrm{Cu}, \mathrm{Zn}, \mathrm{Ni}$ and $\mathrm{Sn}$ with $\mathrm{H}_{2} \mathrm{~S}$ in single-metal and multi-metal systems, Chemosphere 73 (2008) 1448-1452.

[3] J. Cao, G. Zhang, Z. Mao, Z. Fang, C. Yang, Precipitation of valuable metals from bioleaching solution by biogenic sulfides, Miner. Eng. 22 (2009) 289-295.

[4] A.M. Jiménez-Rodríguez, M.M. Durán-Barrantes, R. Borja, E. Sánchez, M.F. Colmenarejo, F. Raposo, Heavy metals removal from acid mine drainage water using biogenic hydrogen sulphide and effluent from anaerobic treatment: Effect of pH, J. Hazard. Mater. 165 (2009) 759-765.

[5] A. Luptakova, M. Kusnierova, Bioremediation of acid mine drainage contaminated by SRB, Hydrometallurgy 77 (2005) 97-102.

[6] A.S. Sheoran, V. Sheoran, R.P. Choudhary, Bioremediation of acid-rock drainage by sulphate-reducing prokaryotes: a review, Miner. Eng. 23 (2010) 1073-1100.

[7] R.P. van Hille, K.A. Peterson, A.E. Lewis, Copper sulphide precipitation in fluidised bed reactor, Chem. Eng. Sci. 60 (2005) 2571-2578.

[8] M. Al-Tarazi, A.B.M. Heesink, M.O.J. Azzam, S.A. Yahya, G.F. Versteeg, Crystallization kinetics of $\mathrm{ZnS}$ precipitation; an experimental study using the mixed-suspension-mixed-product-removal (MSMPR) method, Cryst. Res. Technol. 39 (2004) 675-685.

[9] J.L. Huisman, G. Schouten, C. Schultz, Biologically produced sulphide for purification of process streams, effluent treatment and recovery of metals in the metal and mining industry, Hydrometallurgy 83 (2006) 106-113.

[10] A.E. Lewis, Review of metal sulphide precipitation, Hydrometallurgy 104 (2010) 222-234.

[11] E. Sahinkaya, B. Özkaya, A.H. Kaksonen, J.A. Puhakka, Sulfidogenic fluidizedbed treatment of metal-containing wastewater at low and high temperatures, Biotechnol. Bioeng. 96 (2007) 1064-1072.

[12] A. Lewis, R. van Hille, An exploration into the sulphide precipitation method and its effect on metal sulphide removal, Hydrometallurgy 81 (2006) 197-204.

[13] A. Lewis, A. Swartbooi, Factors affecting metal removal in mixed sulfide precipitation, Chem. Eng. Technol. 29 (2006) 277-280.

[14] N. Karbanee, R.P. van Hille, A.E. Lewis, Controlled nickel sulfide precipitation using gaseous hydrogen sulfide, Ind. Eng. Chem. Res. 47 (2008) 1596-1602.

[15] R.M.M. Sampaio, R.A. Timmers, N. Kocks, V. André, M.T. Duarte, E.D. van Hullebusch, F. Farges, P.N.L. Lens, Zn-Ni sulfide selective precipitation: the role of supersaturation, Sep. Purif. Technol. 74 (2010) 108-118.
[16] A.H.M. Veeken, L. Akoto, L.W. Hulshoff Pol, J. Weijma, Control of the sulfide $\left(S^{2-}\right)$ concentration for optimal zinc removal by sulfide precipitation in a continuously stirred tank reactor, Water Res. 37 (2003) 3709-3717.

[17] J. Mydlarz, A.G. Jones, An assessment of MSMPR crystallization kinetics data for systems modelled by size-dependent crystal growth rate functions, Chem. Eng. J. 55 (1994) 69-80.

[18] J. Gomez-Morales, J. Torrent-Burgues, R. Rodriguez-Clemente, Crystal size distribution of hydroxyapatite precipitated in a MSMPR reactor, Cryst. Res. Technol. 36 (2001) 1065-1074.

[19] S.M. Bertolino, I.C.B. Rodrigues, R. Guerra-Sá, S.F. Aquino, V.A. Leão, Implications of volatile fatty acid profile on the metabolic pathway during continuous sulfate reduction, J. Environ. Manage. 103 (2012) 15-23.

[20] APHA, Standard Methods for the examination of water and wastewater, 21st ed., 2005.

[21] Brasil, Resolução 357 - Classificação dos corpos de água e diretrizes ambientais para seu enquadramento, in: CONSELHO NACIONAL DO MEIO AMBIENTE (CONAMA) (Ed.), Mininstério do Meio-Ambiente, Brazil, 2005, pp. 27.

[22] R.M.M. Sampaio, R.A. Timmers, Y. Xu, K.J. Keesman, P.N.L. Lens, Selective precipitation of $\mathrm{Cu}$ from $\mathrm{Zn}$ in a $\mathrm{pS}$ controlled continuously stirred tank reactor, J. Hazard. Mater. 165 (2009) 256-265.

[23] G. Esposito, A. Veeken, J. Weijma, P.N.L. Lens, Use of biogenic sulfide for ZnS precipitation, Sep. Purif. Technol. 51 (2006) 31-39.

[24] C.Y. Tai, P.-C. Chen, Nucleation, agglomeration and crystal morphology of calcium carbonate, AlChE J. 41 (1995) 68-77.

[25] T.P. Mokone, R.P.v. Hille, A.E. Lewis, Mechanisms responsible for particle formation during metal sulphide precipitation processes, in: International Mine Water Conference, Pretoria, South, Africa, 2009, pp. 343-350.

[26] T.P. Mokone, A.E. Lewis, R.P. van Hille, Effect of post-precipitation conditions on surface properties of colloidal metal sulphide precipitates, Hydrometallurgy 119-120 (2012) 55-66.

[27] B. Hutton, I. Kahan, T. Naidu, P. Gunther, Operating and maintenance experience at the eMalahleni Water Reclamation Plant, in: W. Pullis (Ed.), International Mine Water Conference, Pretoria, South Africa, 2009, pp. 415-430.

[28] H. Dijkman, J. Boonstra, R.W. Lawrence, D. Kratochvil, C.J.N. Buisman, Optimization of metallurgical processes using high rate biotechnology, in: Conference of Metallurgists 2002, Canadian Institute of Mining and Metallurgy, Montreal, 2002, pp. 273-282.

[29] O. Lopez, D. Sanguinetti, M. Bratty, D. Kratochvil, Green technologies for sulphate and metal removal in mining and metallurgical effluents, in: J. Wiertz, C. Moran (Eds.), Enviromine Conference, Santiago, Chile, 2009, pp. 55.

[30] F. Anjum, M. Shahid, A. Akcil, Biohydrometallurgy techniques of low grade ores: a review on black shale, Hydrometallurgy 117-118 (2012) 1-12. 